\title{
Multiscale computer modeling of spreading depolarization in brain slices
}

\author{
Craig Kelley ${ }^{1 *}$ Adam JH Newton ${ }^{2}$, Sabina Hrabetova ${ }^{3,4}$, Robert A. McDougal ${ }^{5,6,7}$, William W Lytton ${ }^{2,4,8,9}$ \\ 1. Program in Biomedical Engineering, SUNY Downstate Health Sciences University \& NYU Tandon \\ School of Engineering, Brooklyn, NY, USA, 11203
}

2. Department of Physiology \& Pharmacology, SUNY Downstate Health Sciences University, Brooklyn, NY, USA, 11203

3. Department of Cell Biology, SUNY Downstate Health Sciences University, Brooklyn, NY, USA, 11203

4. The Robert F. Furchgott Center for Neural and Behavioral Science, Brooklyn, NY, USA, 11203

5. Department of Biostatistics, Yale University, New Haven, CT, USA, 06513

6. Yale Center for Medical Informatics, Yale University, New Haven, CT, USA, 06513

7. Program in Computational Biology and Bioinformatics, Yale University, New Haven, CT, USA, 06513

8. Department of Neurology, SUNY Downstate Health Sciences University, Brooklyn, NY, USA, 11203

9. Department of Neurology, Kings County Hospital Center, Brooklyn, NY, USA, 11203

* craig.kelley@downstate.edu

Conflict of interest statement: The authors declare no competing financial interests.

Acknowledgements: This work was funded by NIH NIMH R01MH086638 and NSF Grant Internet2 E-CAS 1904444. We wish to thank Drs. Rena Orman, Mark Stewart, Richard Kollmar, and John Kubie (SUNY Downstate) for useful discussions on this topic.

1 Abstract

Spreading depolarization (SD) is a slow-moving wave of neuronal depolarization accompanied by a breakdown of ion concentration homeostasis, followed by long periods of neuronal silence (spreading depression), and associated with several neurological conditions. We developed multiscale (ions to tissue slice) computer models of SD in brain slices using the NEURON simulator: 36,000 neurons (2 voltage-gated ion channels; 3 leak channels; 3 ion exchangers/pumps) in the extracellular space (ECS) of a slice ( $1 \mathrm{~mm}$ sides, varying thickness) with ion $\left(\mathrm{K}^{+}, \mathrm{Cl}^{-}, \mathrm{Na}^{+}\right)$and $\mathrm{O}_{2}$ diffusion and equilibration with a surrounding bath. Glia and neurons cleared $\mathrm{K}^{+}$from the ECS via $\mathrm{Na}^{+} / \mathrm{K}^{+}$pumps. SD propagated through the slices at realistic speeds of $2-5 \mathrm{~mm} / \mathrm{min}$, which was augmented by $25-30 \%$ in models incorporating the effects of hypoxia or of propionate. In both cases, the speedup was mediated principally by ECS shrinkage. 
Our model allows us to make the following testable predictions: 1. SD can be inhibited by enlarging ECS volume; 2. SD velocity will be greater in areas with greater neuronal density, total neuronal volume, or larger/more dendrites; 3. SD is all-or-none: initiating $\mathrm{K}^{+}$bolus properties have little impact on SD speed; 4. Slice thickness influences SD due to relative hypoxia in the slice core, exacerbated by SD in a pathological cycle; 5. Higher neuronal spike rates and faster spread will be observed in the core than the periphery of perfused slice during SD.

\section{Significance}

Spreading depolarization (SD) is a slow moving wave of electrical and ionic imbalances in brain tissue and is a hallmark of several neurological disorders. We developed a multiscale computer model of brain slices with realistic neuronal densities, ions, and oxygenation. Our model shows that SD is exacerbated by and causes hypoxia, resulting in strong SD dependence on slice thickness. Our model also predicts that the velocity of SD propagation is not dependent on its initiation, but instead on tissue properties, including the amount of extracellular space and the total area of neuronal membrane, suggesting faster SD following ischemic stroke or traumatic brain injury.

\section{Introduction}

Spreading depolarization (SD), is a slow-moving (1.7-9.2 $\mathrm{mm} / \mathrm{min})$, long-lasting (minutes) wave of neuronal depolarization accompanied by a breakdown in homeostatic maintenance of intra- and extracellular ion concentrations, and associated with reduced neuronal activity (spreading depression) [Woitzik et al., 2013, Newton et al., 2018, Cozzolino et al., 2018, Dreier, 2011]. SD has been observed in a number of species, can be elicited experimentally both in vivo and in brain slices, and has been implicated in several neurological conditions, including ischemia, migraine, traumatic brain injury, and epilepsy [Cozzolino et al., 2018]. SD is difficult to detect in humans noninvasively [Zandt et al., 2015], making it important to study SD in experimental preparations and computer simulation to better understand its role in human disease, and possible treatments.

SD has been studied in brain slices from a wide range of species and brain regions, including neocortex, hippocampus, brainstem, and retina [Martins-Ferreira et al., 2000, Balestrino et al., 
1988, Aitken et al., 1998, Müller and Somjen, 1998, Andrew, 2016, Devin Brisson et al., 2013, Hrabe and Hrabetova, 2019]. It can be triggered experimentally by various means, including electrical stimulation; mechanical insult; $\mathrm{K}^{+}$, glutamate, and ouabain application [Cozzolino et al., 2018]. In brain slices, it can be elicited by inducing hypoxia [Balestrino et al., 1988, Aitken et al., 1991, Müller and Somjen, 1998], and it can be facilitated by applying propionate to the slice [Tao et al., 2002, Hrabe and Hrabetova, 2019]

In this paper, we use multiscale computational modeling of SD to relate the microscopic levels of ion and $\mathrm{O}_{2}$ diffusion, channels, and pumps to the neuronal level of cell spiking up to the macroscopic level of tissue activation patterns (Fig. 1). Our baseline model is composed of 36,000 biophysically detailed point-neurons in an extracellular space (ECS) of a square slice (1 mm sides, $400 \mu \mathrm{m}$ thick) with $\mathrm{O}_{2}$ perfusion and ion flux with a surrounding bath where relevant concentrations are held constant at their baseline values in the ECS. We simulated SD in both perfused and hypoxic slices. Our model confirms that SD speed is augmented by propionate and hypoxia and suggests that changing the ECS is the principle mechanism through which they influence SD. We predict that SD speed will change with slice thickness due to core hypoxia, increase with the total neuronal surface area in the tissue. SD speeds in all conditions were enhanced by hypoxia. We also predict that increasing the size of the ECS relative to the tissue will inhibit SD. Finally, we identified a depth-dependent relationship with greater SD propagation through core of the slice compared to the periphery.

\section{Materials and methods}

We developed a tissue-scale model of SD in slices by extending the framework developed by Wei $e t$ al. 2014 [Wei et al., 2014] from a single cell in its local micro-environment to 36,000 cells (baseline) embedded in an ECS. We used the NEURON simulator and its extracellular reaction-diffusion framework (RxD-ECS) to simulate the electrophysiology of those neurons, the exchange of ions between them and the ECS, diffusion of ions and $\mathrm{O}_{2}$ through the slice, and exchange of ions and $\mathrm{O}_{2}$ between the slice and the bath solution in which it was submerged [Newton et al., 2018]. Our model is not specific to any particular brain area, as we aimed to reproduce general properties applicable to different brain regions and to different pathophysiologies. 


\section{Model}

Model neurons were all point-neurons (1 compartment) which included voltage-gated $\mathrm{K}^{+}$and $\mathrm{Na}^{+}$ channels; $\mathrm{Na}^{+}, \mathrm{K}^{+}$, and $\mathrm{Cl}^{-}$leak channels; $\mathrm{K}^{+}-\mathrm{Cl}^{-}$(KCC2) [Payne et al., 2003] and $\mathrm{Na}^{+}-\mathrm{K}^{+}-\mathrm{Cl}^{-}$ (NKCC1) cotransporters; and $\mathrm{Na}^{+} / \mathrm{K}^{+}$pumps (Fig. 1), ported from Wei et al. (2014) [Wei et al., 2014]. In order for cells to balance a steady-state resting membrane potential in a slice with dynamic ion and $\mathrm{O}_{2}$ concentrations, we added a passive electrical conductance with reversal potential $\mathrm{E}_{\mathrm{rev}}=-70 \mathrm{mV}$ and conductance $g=0.1 \mathrm{mS} / \mathrm{cm}^{2}$. Neurons were closed-ended cylinders (no flux from ends).

To explore the effects of surface area to volume $(\mathrm{S}: \mathrm{V})$ ratio, we used RxD-ECS to independently define a neural surface entirely separated from its volume - hence NOT following the overall geometry of the structure. This is possible since we used the concept of fractional volumes, rather than providing actual volume-occupying structures [McDougal et al., 2013]. Neuronal volume fraction $\beta_{\text {nrn }}$ is defined as the ratio of total neuronal volume $\left(\mathrm{Vol}_{\mathrm{nrn}}\right)$ to total tissue volume: $\beta_{\mathrm{nrn}}=\frac{\mathrm{Vol}_{\mathrm{nnn}}}{\mathrm{Vol}_{\text {tissue }}}$ (compare with $\alpha_{E C S}$ which is $\frac{V_{\text {olecs }}}{\text { Vol tissue }_{\text {tice }}}$ [Rice and Russo-Menna, 1998]. Given a chosen tissue volume, $\beta_{\text {nrn }}$, and a total number of neurons $N_{\text {nrn }}$ (based on cell density times $\mathrm{Vol}_{\text {tissue }}$ ), the volume of a single neuron vol $_{\mathrm{nrn}}$ is:

$$
\operatorname{vol}_{\mathrm{nrn}}=\frac{\beta_{\mathrm{nrn}} \cdot \mathrm{Vol}_{\mathrm{tissue}}}{N_{\mathrm{nrn}}}
$$

(Note case: $\mathrm{vol}_{\mathrm{nrn}}$ for single cell; $\mathrm{Vol}_{\mathrm{nrn}}$ for cumulative neuronal volume) In NEURON, neural compartments are cylinders, omitting the ends. In the present case, our point-neurons are each a single cylinder, defined by length $\mathrm{L}$ and diameter $\mathrm{d}$. Setting $L=d$ for simplicity, the surface area is defined as $S_{\mathrm{nrn}}=\pi \cdot d^{2}$. The associated volume, calculated for this cylinder, was not used. We therefore used RxD-ECS's FractionalVolume class to scale the volume of a cell with the desired S:V to vol ${ }_{n r n}$, while the cell retains its original $S_{\mathrm{nrn}}[\mathrm{McD}$ ougal et al., 2013].

To establish a biologically realistic range for $\mathrm{S}: \mathrm{V}$, we analyzed morphological reconstructions of neurons from neuromorpho. org. We used results for cells with intact soma and dendritic reconstructions in 3 dimensions from animals older than two weeks. In rat neocortex, average S:V was 3.4 $\pm 1.2 \mu \mathrm{m}^{-1}$ for both pyramidal cells ( $\left.\mathrm{n}=96\right)$ and interneurons $(\mathrm{n}=108)$ [Radman et al., 2009, Boudewijns 
et al., 2013, Larkum et al., 2004, Vetter et al., 2001, Meyer et al., 2010, Kubota, 2014]. Higher S:V was grossly associated with larger dendritic trees; $\mathrm{S}: \mathrm{V}$ scales inversely with diameter in cylindrical structures (excluding ends): $\mathrm{S}: \mathrm{V}=\frac{4}{d}$. For our baseline simulations, we used $\mathrm{S}: \mathrm{V}=3.0 \mu \mathrm{m}^{-1} ; \beta_{n r n}=0.24$; neuronal density $=90 \cdot 10^{3}$ neurons $/ \mathrm{mm}^{3}$, typical of neocortex [Rice and Russo-Menna, 1998, Keller et al., 2018].

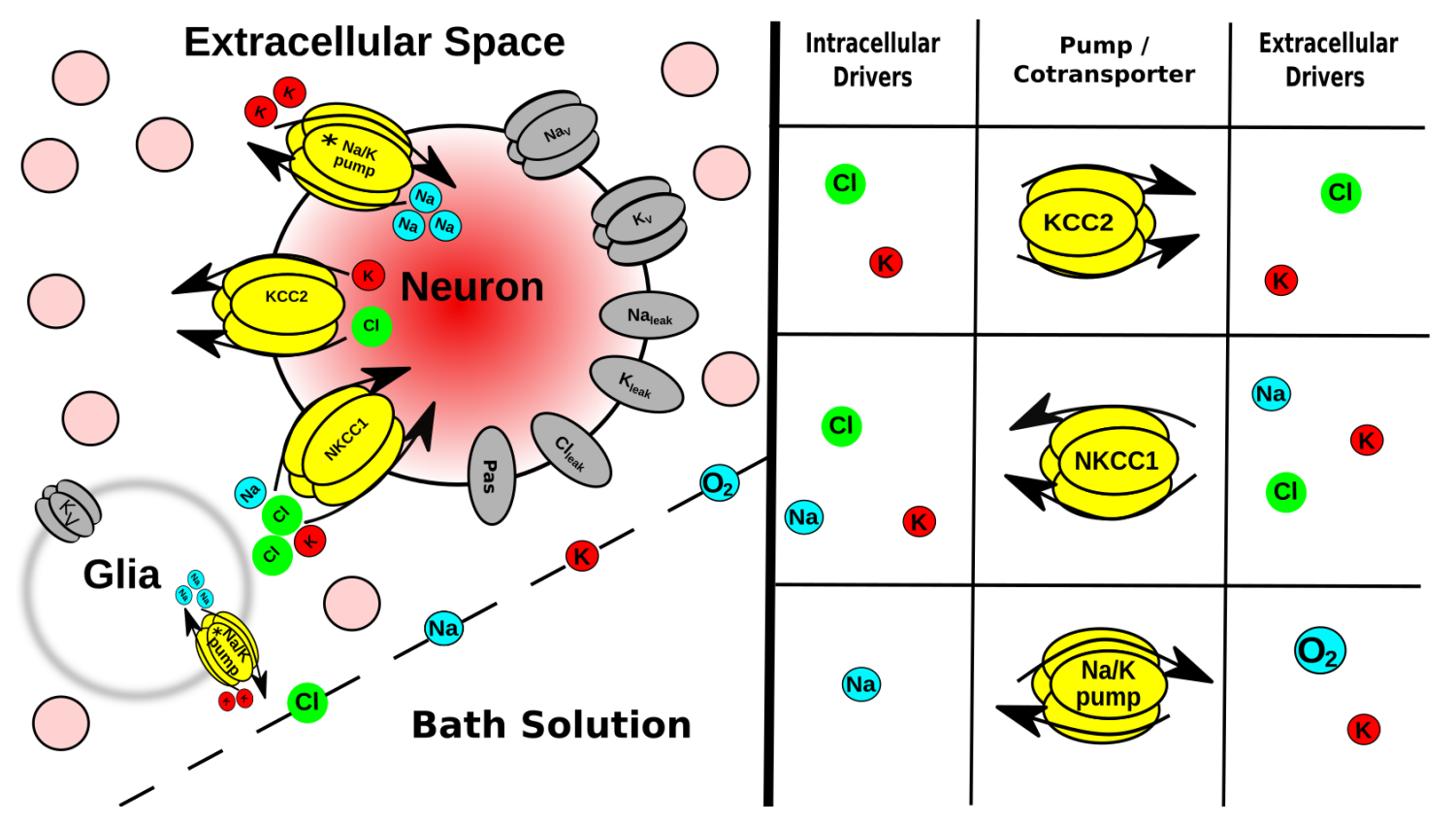

Figure 1: Multiscale model expanded. Tissue scale: A few of the $36 \cdot 10^{3}$ neurons (pink circles) in brain slice submerged in bath; glia are not explicitly modeled, instead represented as a field of sinks in every ECS voxel. Cell scale: Each neuron has ion channels, 2 co-exchangers; $\mathrm{Na}^{+} / \mathrm{K}^{+}$pump (asterisk indicates ATP $/ \mathrm{O}_{2}$ dependence) Ions are well-mixed within each neuron (no intracellular diffusion). Protein scale: Table (right) indicates species that control the activity of the intrinsic mechanisms in neurons and in glialfield. [Ion] scale: Ions diffuse between ECS voxels by Fick's law using diffusion coefficients in Table 1.

Simulated slices were $1 \mathrm{~mm} \times 1 \mathrm{~mm}$ and ranged in thickness $100-800 \mu \mathrm{m}$ with $45 \cdot 10^{3}-120 \cdot 10^{3}$ neurons $/ \mathrm{mm}^{3}$. The baseline simulation was $400 \mu \mathrm{m}$ slice with $90 \cdot 10^{3}$ neurons $/ \mathrm{mm}^{3}\left(36 \cdot 10^{3}\right.$ neurons in total). Neurons were situated randomly throughout extracellular space (ECS) with diffusion of $\mathrm{Na}_{E C S}^{+}$, $\mathrm{K}_{E C S}^{+}, \mathrm{Cl}_{E C S}^{-}$, and $\mathrm{O}_{2}$ with diffusion coefficients (D) given in Table 1. Extracellular volume fraction ( $\alpha_{E C S}:$ ratio of extracellular space volume to total tissue volume) and tortuosity ( $\lambda_{E C S}$ : hindrance to diffusion in tissue compared to free medium) were the same for all ions. This results in a lower effective diffusion coefficient $\left(D^{*}\right)$ for ions but not $\mathrm{O}_{2}$, which diffuses through the slice unhindered. Diffusion through the ECS was calculated with a voxel size of $25 \mu \mathrm{m}$ x $25 \mu \mathrm{m}$ x $25 \mu \mathrm{m}$. Simulated slices were 
submerged in simulated bath solution where ion and $\mathrm{O}_{2}$ concentrations were equivalent to those estimated for ECS (Table 1, [Cressman et al., 2009, Wei et al., 2014]) with Dirichlet boundary conditions.

\begin{tabular}{l|c|c|c}
\hline Species & $\mathrm{D}\left(\cdot 10^{-5} \mathrm{~cm}^{2} / \mathrm{s}\right)$ & Intracellular Concentration $(\mathrm{mM})$ & ECS Concentration $(\mathrm{mM})$ \\
\hline $\mathrm{K}^{+}$ & 2.62 & 140.0 & 3.5 \\
\hline $\mathrm{Na}^{+}$ & 1.78 & 18.0 & 144.0 \\
\hline $\mathrm{Cl}^{-}$ & 2.10 & 6.0 & 130.0 \\
\hline $\mathrm{O}_{2}$ & 3.30 & 0.1 & 0.1 \\
\hline
\end{tabular}

Table 1: Diffusion coefficients and baseline concentrations for ions and $\mathrm{O}_{2}$ in perfused slice [Haynes, 2014, Samson et al., 2003, Wei et al., 2014]

In the perfused slice, $\left[\mathrm{O}_{2}\right]=0.1 \mathrm{mM}$ (corresponding to a bath solution aerated with $95 \% \mathrm{O}_{2}: 5 \% \mathrm{CO}_{2}$ [Wei et al., 2014]), $\alpha_{E C S}=0.2$, and $\lambda_{E C S}=1.6$ [Syková and Nicholson, 2008]. We modeled the effects of hypoxia by decreasing $\left[\mathrm{O}_{2}\right]$ to $0.01 \mathrm{mM}$, decreasing $\alpha_{E C S}$ to 0.07 , and increasing $\lambda_{E C S}=1.8$ [Pérez-Pinzón et al., 1995, Zoremba et al., 2008]. We modeled the effects of propionate, which "primes" the tissue for $\mathrm{SD}$, by reducing $\alpha_{E C S}$ to 0.12 and total $\mathrm{Cl}^{-}$content in the slice by $50 \%$, but keeping $\left[\mathrm{O}_{2}\right]=$ $0.1 \mathrm{mM}$ and $\lambda_{E C S}=1.6[$ Hrabe and Hrabetova, 2019].

Studies have shown that $\alpha_{E C S}$ changes dynamically over the course of SD [Mazel et al., 2002, Hrabe and Hrabetova, 2019]. Since the biophysics of ECS changes during SD have not been elucidated at the time scale of our simulations, for a subset of simulations we incorporated these changes phenomenologically to obtain $\alpha_{\mathrm{ECS}}$ 0.05-0.1 during passage of the SD [Mazel et al., 2002]. In each ECS voxel:

$$
\frac{d \alpha_{\mathrm{ECS}}}{d t}=\left(5 \cdot 10^{-7}\right) \cdot\left(\left[K^{+}\right]_{\mathrm{ECS}}-3.5\right) \cdot\left(\left[K^{+}\right]_{\mathrm{ECS}}-70.0\right) \cdot \alpha_{\mathrm{ECS}}
$$

This model of dynamic $\alpha_{E C S}$ only accounts for the drop in $\alpha_{E C S}$ during SD, not its recovery after SD, which occurs on the time-scale of minutes [Mazel et al., 2002, Hrabe and Hrabetova, 2019].

Glia were modeled by a background voltage-gated $\mathrm{K}^{+}$current and $\mathrm{Na}^{+} / \mathrm{K}^{+}$pump in each ECS voxel [Cressman et al., 2009, Øyehaug et al., 2012, Wei et al., 2014], rather than as individual cells.

\section{Simulations}

SD was initiated by elevating initial $\left[\mathrm{K}^{+}\right]_{\mathrm{ECS}}$ within a spherical bolus at the center of the slice at $\mathrm{t}=0$. Baseline simulations were run with $\mathrm{K}^{+}$bolus with radius $=100 \mu \mathrm{m} ;\left[\mathrm{K}^{+}\right] \mathrm{ECS}=70 \mathrm{mM}$. To follow the 
position of SD over time, we tracked the position of the $\mathrm{K}^{+}$wavefront: the furthest location where $\left[\mathrm{K}^{+}\right]_{\text {ECS }}$ exceeded $15 \mathrm{mM}$. Propagation speed was indicated as 0 if the $\mathrm{K}^{+}$wave didn't propagate. Most simulations ran for 10 seconds, which was sufficient for SD to propagate throughout the entire slice.

In the course of this study, we ran over 600 simulations covering a range of slice sizes, cell densities, and durations on a number of different architectures. Simulating a $1 \mathrm{~mm}$ x $1 \mathrm{~mm}$ x $400 \mu \mathrm{m}$ slice with a cell density of $90 \mathrm{k}$ neurons $/ \mathrm{mm}^{3}\left(36 \cdot 10^{3}\right.$ neurons) for $10 \mathrm{~s}$ of simulation-time took approximately 12.5 hours on a parallel Linux system using 48 nodes on a $2.40 \mathrm{GHz}$ Intel Xeon E5-4610 CPU. Incorporating dynamic $\alpha_{E C S}$ into the same model on the same machine increased simulation time to approximately 18 hours. Due to these computational limitations we restricted out simulations to $10 \mathrm{sec}$ which meant that we could not continue to the termination phase of SD which would require considerably greater temporal and spatial scales. Simulations were run using Neuroscience Gateway [Sivagnanam et al., 2013], Google Cloud Platform, and the on-site high performance computer at SUNY Downstate Health Sciences University. All code for simulation, data analysis, and visualization was written in Python/NEURON and is available on GitHub and ModelDB.

\section{Results}

In our model of an $\mathrm{O}_{2}$-perfused slice, a small bolus of elevated $\mathrm{K}^{+}(70 \mathrm{mM}, 100 \mu$ m radius) initiated a propagating $\mathrm{K}^{+}$wave with associated spreading depolarization (SD) producing neuronal spiking (Fig. 2). The $\mathrm{K}^{+}$wave travelled radially outward from the bolus in 3 dimensions towards the edges of the slice at 2.4 $\mathrm{mm} / \mathrm{min}$, comparable to optical and electrophysiological measurements of SD propagation velocity in brain slices [Aitken et al., 1998, Joshi and Andrew, 2001, Hrabe and Hrabetova, 2019]. Within the $\mathrm{K}^{+}$bolus, most cells fired a single spike and went immediately into depolarization block. Outside the $\mathrm{K}^{+}$bolus, cells fired a 200-900 ms burst of action potentials as $\left[\mathrm{K}^{+}\right]_{\mathrm{ECS}}$ increased around them. During the course of the SD-associated burst, instantaneous firing rates increased to as high as $250 \mathrm{~Hz}$ with decreasing spike heights during the burst, comparable to experimental observations [Devin Brisson et al., 2013, Lemaire et al., 2021]. Cells then remained in depolarization block for the full $10 \mathrm{~s}$ measured (see Methods for computational limitations) [Devin Brisson et al., 2013, Andrew, 2016]. Spreading depolarization, seen intracellularly, produced $\mathrm{Na}^{+}$channel inactivation and prevented further spiking. Absence of spiking 
would be seen extracellularly as spreading depression - a silent region in the slice. The $\mathrm{K}^{+}$wave and spreading depolarization (SD) were coincident in time and space, with spreading depression following closely behind; we primarily followed the $\mathrm{K}^{+}$wave since this was easiest to localize across conditions.

A)

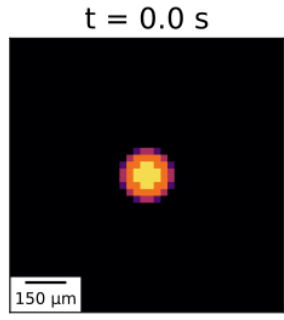

B)

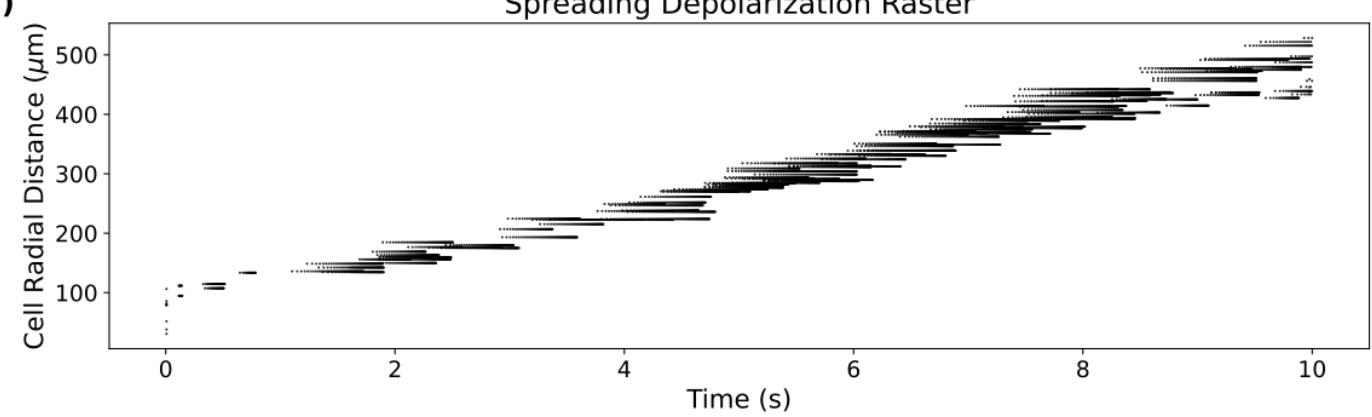

Figure 2: Spreading $\mathrm{K}^{+}$and depolarization waves in perfused slice. A. $\left[\mathrm{K}^{+}\right]_{\mathrm{ECS}}$ averaged across slice depth $(400 \mu \mathrm{m})$ at 4 time points during SD. B. Spike raster plot of 250 randomly-selected neurons (out of 36 $\cdot 10^{3}$ ) during SD. Cells are ordered on $\mathrm{y}$-axis by their radial distance from the center of the $\mathrm{K}^{+}$bolus. Blank area under spikes represents region of spreading depression. Baseline values: $\left[\mathrm{O}_{2}\right]=0.1 \mathrm{mM} ; \alpha_{E C S}=0.2$; $\lambda_{E C S}=1.6 ;\left[\mathrm{Cl}^{-}\right]_{E C S}=130.0 \mathrm{mM} ;\left[\mathrm{Cl}^{-}\right]_{i}=6.0 \mathrm{mM}$.

SD was an all-or-none process; it could only be initiated above a certain threshold measured either in concentration $-\left[\mathrm{K}^{+}\right]_{\mathrm{ECS}} \geq 20 \mathrm{mM}$ (bolus diameter $200 \mu \mathrm{m}$ ), or in bolus diameter - diameter $\geq 100 \mu \mathrm{m}$ $\left(\left[\mathrm{K}^{+}\right]_{\mathrm{ECS}} 70 \mathrm{mM}\right)\left(\right.$ Fig. 3). Beyond these thresholds, different $\mathrm{K}^{+}$bolus concentrations and diameter had only a minimal effect on wave speed.

Underpinning SD was a wave of pronounced imbalance of transmembrane ion concentrations (Fig. 4). Excess $\mathrm{K}^{+}$is briefly eliminated from the ECS via neural and glial homeostatic mechanisms. Once the $\mathrm{K}^{+}$ wave arrived however, the cells dumped large quantities of $\mathrm{K}^{+}$into the ECS due to the burst and subsequent prolonged depolarization (note rapid depletion of $\left[\mathrm{K}^{+}\right]_{\mathrm{i}}-$ Fig. $4 \mathrm{~B}$ ). The $\mathrm{Na}^{+} / \mathrm{K}^{+}$pump activity 


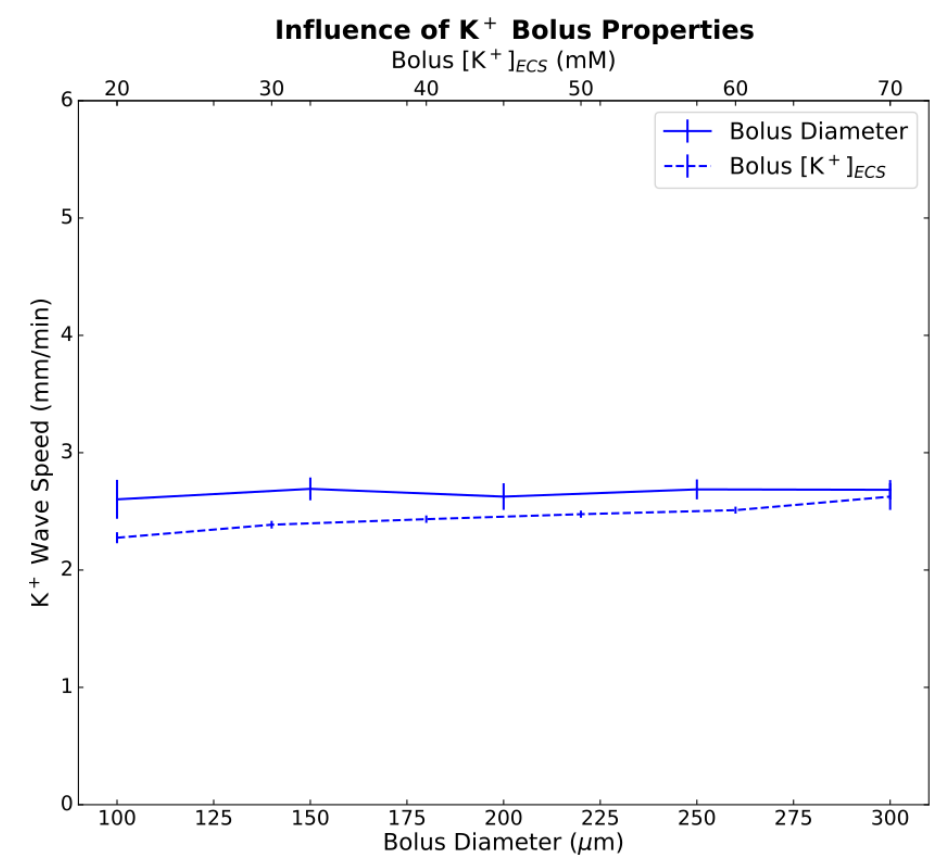

Figure 3: Diameter and concentration of the $\mathrm{K}^{+}$bolus had minor effects on $\mathrm{K}^{+}$wave speed.

Mean and standard deviations $(n=5)$ for $\mathrm{K}^{+}$wave speed by bolus diameter (solid line; bolus $\left[\mathrm{K}^{+}\right]_{\mathrm{ECS}}=70$ $\mathrm{mM} ; 5$ random cell position initializations); bolus concentration (dashed line; diameter $=200 \mu \mathrm{m}$ ).

which contributed to $\mathrm{K}^{+}$elimination from the ECS in the core of the slice created a high demand for $\mathrm{O}_{2}$, exceeding the rate at which it could diffuse in from the bath. This resulted in much of the tissue becoming hypoxic before the arrival of the $\mathrm{K}^{+}$wave (compare rapid fall-off of $\mathrm{O}_{2}$ in Fig. 4E to much slower rise of extracellular $\mathrm{K}^{+}$in Fig. 4F). The rapid spread of $\mathrm{O}_{2}$ deficit explains the total pump failure at intermediate locations in the slice. There were small upward deflections in the first 3 traces in Fig. 4B reflecting homeostatic inward pumping. There was no upward deflection in the other 3 traces $-\mathrm{O}_{2}$ has disappeared before the $\mathrm{K}^{+}$wave arrives. The preservation of pumping in the final, most peripheral, trace of Fig. 4B is due to this measurement being at the edge of the slice, proximal to the $\mathrm{O}_{2}$ source of the bath. Once $\left[\mathrm{K}^{+}\right]_{\text {ECS }}$ reached $\sim 14 \mathrm{mM}$, cellular homeostatic mechanisms totally broke down, with dramatic increases in intracellular $\mathrm{Na}^{+}$and $\mathrm{Cl}^{-}$(Fig. 4C,D).

$\mathrm{K}^{+}$wave propagation was facilitated by incorporating the effects of hypoxia or propionate treatment on the slice (Fig. 5). Simulating the effects of hypoxia $\left(\left[\mathrm{O}_{2}\right]\right.$ to $0.01 \mathrm{mM}$ with decreased $\alpha_{E C S}=0.07$ and increased $\lambda_{E C S}=1.8$ [Pérez-Pinzón et al., 1995, Zoremba et al., 2008]), increased $\mathrm{K}^{+}$wave propagation 

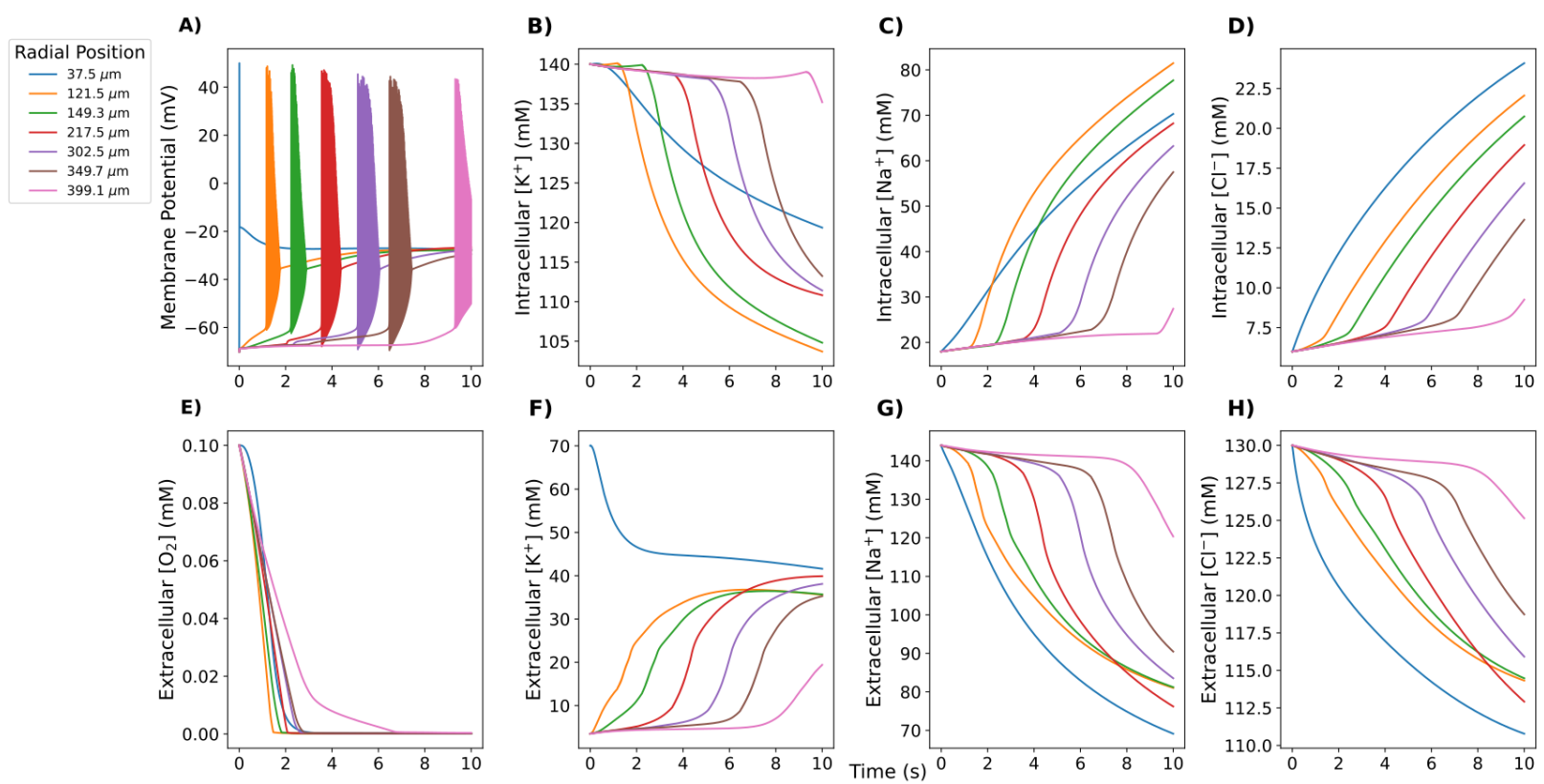

Figure 4: Example traces of $\mathbf{V}_{m e m b}, \mathbf{O}_{2}$ and ion concentrations at 7 locations measured from center of $400 \mu \mathrm{m}$ thick, perfused slice during SD. A. Cells within the $\mathrm{K}^{+}$bolus produced a single spike, while cells in the path of the $\mathrm{K}^{+}$wave fired a burst; all cells remained in depolarization block for seconds afterward. B-C. Intracellular ion concentrations of those same cells. E-H. Extracellular $\mathrm{O}_{2}$ and ion concentrations in ECS voxels at those locations.

speed to $4.5 \mathrm{~mm} / \mathrm{min}$. Simulating propionate application (decreased $\alpha_{E C S}=0.12$; halving $\left[\mathrm{Cl}^{-}\right]_{i}$ and $\left[\mathrm{Cl}^{-}\right]_{E C S}$ [Tao et al., 2002, Hrabe and Hrabetova, 2019]), increased $\mathrm{K}^{+}$wave speed similarly (Fig. 5A).

Comparable speedups were also observed in the depolarization waves (Fig. 5B). Since these manipulations included combined changes to $\left[\mathrm{O}_{2}\right], \mathrm{Cl}^{-}, \alpha_{E C S}$, and/or $\lambda_{E C S}$, we investigated their individual contributions over the relevant ranges. Since both hypoxia and propionate decrease $\alpha_{E C S}$, we also tested increasing $\alpha_{E C S}$ to as high as 0.42 , which has been observed when making the ECS artificially hypertonic [Kume-Kick et al., 2002]. $\alpha_{E C S}$ had the largest influence on propagation, changing $\mathrm{K}^{+}$wave speed by $>2$ $\mathrm{mm} / \mathrm{min}$ over the range tested, while $\mathrm{K}^{+}$wave speed changed by $<0.5 \mathrm{~mm} / \mathrm{min}$ for the ranges of $\left[\mathrm{O}_{2}\right]$, $\lambda_{E C S}$, and $\left[\mathrm{Cl}^{-}\right]$values tested (Fig. $5 \mathrm{C}$ ).

Experimental studies have demonstrated dynamic changes in $\alpha_{E C S}$ occurring during SD, with $\alpha_{E C S}$ dropping to as low as 0.05 at the peak of the depolarization [Mazel et al., 2002, Hrabe and Hrabetova, 2019]. Given the strong influence of constant $\alpha_{E C S}$ on SD propagation (Fig. 5C - orange line), we also explored the influence of dynamic $\alpha_{E C S}$ (Fig. 5A - purple line). Dynamically decreasing $\alpha_{E C S}$ was 
A)

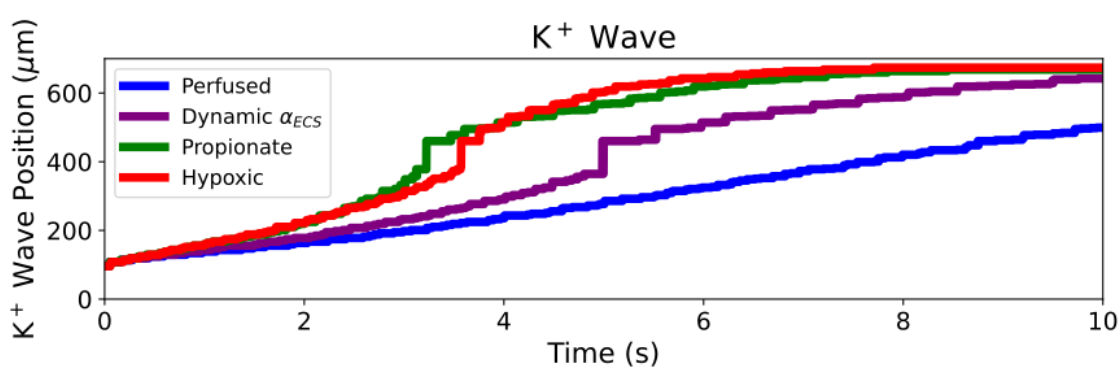

B)

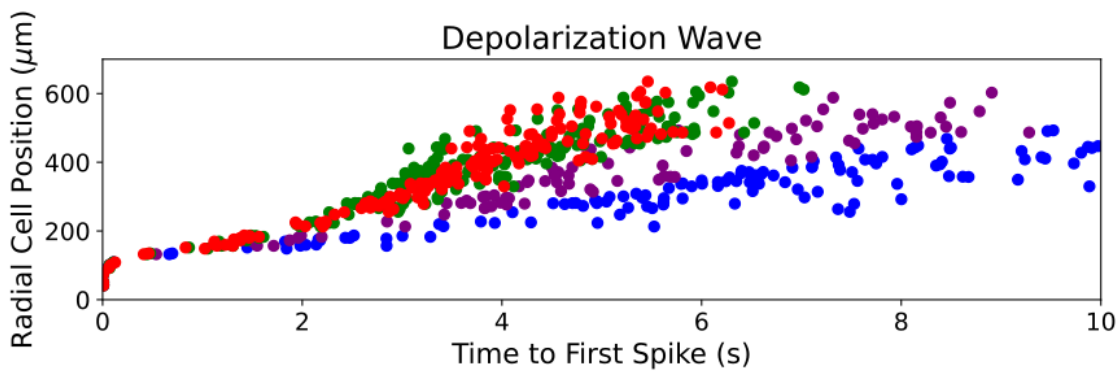

C)

Influence of $\alpha_{E C S}, \lambda_{E C S},\left[\mathrm{Cl}^{-}\right],\left[\mathrm{O}_{2}\right]$

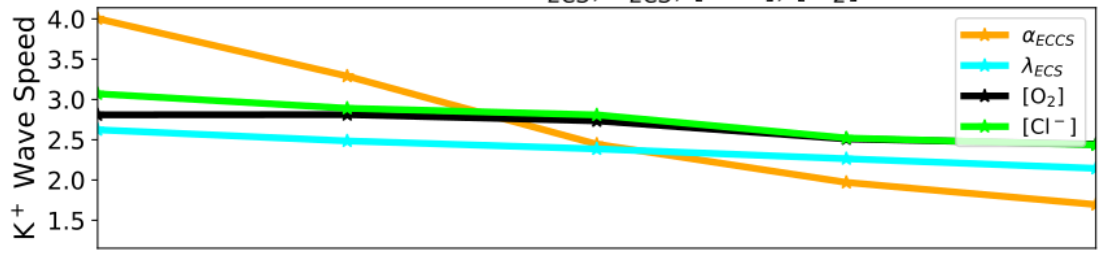

Figure 5: Hypoxia, propionate, and dynamic ECS facilitate SD principally through reducing $\alpha_{\mathbf{E C S}}$. Increasing $\alpha_{\text {ECS }}$ attenuates SD. A. $\mathrm{K}^{+}$wave position over time during SD in perfused, hypoxic, propionatetreated slices, and with dynamic changes in $\alpha_{\mathbf{E C S}}$. Hypoxia and propionate facilitated propagation. B. SD wave, as represented by time to first spike ( 126 of $36 \cdot 10^{3}$ cells). C. $\mathrm{K}^{+}$wave speeds when changing a single variable from baseline (Fig. 2). (x-axis ranges: $\left[\mathrm{O}_{2}\right]=0.01-0.1 \mathrm{mM} ; \alpha_{E C S}=0.07-0.42 ; \lambda_{E C S}=1.4-2.0$; $\left.\left[\mathrm{Cl}^{-}\right]_{E C S}:\left[\mathrm{Cl}^{-}\right]_{i}=3.0: 65.0-6.0: 130.0 \mathrm{mM}\right)$

modeled as a local function of increasing $\left[\mathrm{K}^{+}\right]_{\mathrm{ECS}}$ (see Methods), such that $\alpha_{E C S}$ dropped to 0.06 in the wake of SD, within the experimentally-observed range of 0.05 - 0.1 [Mazel et al., 2002]. Incorporating a dynamic ECS increased the speed of SD propagation in perfused slice from $2.4 \mathrm{~mm} / \mathrm{min}$ to $3.3 \mathrm{~mm} / \mathrm{min}$.

The stereotyped characteristics of neuronal firing patterns during depolarization wave remained unchanged by dynamic changes in $\alpha_{E C S}$.

Different brain areas have different cell densities and their neurons have different morphological characteristics. We manipulated our generic model so as to explore 3 properties of neural tissue organization and shape: neuronal surface area to volume ratio $(\mathrm{S}: \mathrm{V})$; fraction of tissue volume occupied by 
neurons ( $\left.\beta_{\mathrm{nrn}}\right)$; and cell density (Fig. 6). Neuronal S:V varies across cell types, brain regions, and species. Examination of representative morphologies showed that $\mathrm{S}: \mathrm{V}$ values are generally in a range of $2-10 \mu \mathrm{m}^{-1}$ (see Methods), with neocortical principal cell S:V of $3.4 \pm 1.2 \mu \mathrm{m}^{-1}$ (n=96) significantly greater than brainstem principal cell $\mathrm{S}: \mathrm{V}$ of $2.2 \pm 1.2 \mu \mathrm{m}^{-1}$ ( $\mathrm{n}=74 ; \mathrm{p}<0.001$, Mann-Whitney U test) [Williams et al., 2019, Ros et al., 2010, Núñez-Abades et al., 1994, Raslan et al., 2014, Radman et al., 2009, Boudewijns et al., 2013, Larkum et al., 2004, Vetter et al., 2001, Meyer et al., 2010]. Neuronal volume fraction $\beta_{\text {nrn }}$ may differ with different brain areas, and will differ under the pathological condition of cytotoxic edema. Cell density varies across different neural areas.

Realistic $\left(>1 \mu \mathrm{m}^{-1}\right) \mathrm{S}: \mathrm{V}$ was necessary for initiating SD (Fig. 6A) - SD could not be initiated using the actual 3D geometry of single-cylinder point-neurons with diameter and height selected to produce baseline $\beta_{\text {nrn }}$ of $0.24\left(\mathrm{~S}: \mathrm{V}=0.02 \mu \mathrm{m}\right.$ with $90 \mathrm{k}$ neurons $/ \mathrm{mm}^{3}$, perfused or hypoxic). Above this threshold, $\mathrm{K}^{+}$wave speed increased with S:V. $\mathrm{K}^{+}$wave speed also increased with increased $\beta_{\text {nrn }}$ while keeping S:V and cell density constant (Fig. 6B). Cell density effects were less marked, whether through keeping surface area and volume constant (Fig. 6C), or keeping $\beta_{\text {nrn }}$ and S:V constant (Fig. 6D). In all cases, change with altered parameters was more pronounced in the hypoxic slice. Pooled together, we found a near linear relationship of $\mathrm{K}^{+}$wave speed with total neuronal surface area in the tissue (Fig. 6E).

Slice thickness $(100-800 \mu \mathrm{m})$ influenced SD by altering the ability of $\mathrm{O}_{2}$ to penetrate to the tissue core (Fig. 7). The $\mathrm{K}^{+}$wave could not be initiated in $100 \mu \mathrm{m}$ perfused slice - SD was not sustainable with full $\mathrm{O}_{2}$ availability. With increasing thickness, an increasingly hypoxic core (despite $\mathrm{O}_{2}$ perfusion of the bath) allowed $\mathrm{K}^{+}$wave speed to increase from 1.7-2.1 mm/min over 200-400 $\mu$ m thickness (Fig. 7A). Above $400 \mu \mathrm{m}$ there was no increased speed with increased thickness. This pattern of increased speedup to $400 \mu \mathrm{m}$ was also seen in our hypoxic condition, but with faster speeds and proportionally more speed increase: $2.8-4.9 \mathrm{~mm} / \mathrm{min}$. The important effect of relative hypoxia suggested the possibility of differential $\mathrm{K}^{+}$spread in the slice core vs. the periphery; this was demonstrable primarily in our perfused case (core: Fig. 7C, 7A - blue dashed, vs periphery: 7B, 7A - blue solid). $\mathrm{K}^{+}$wave speeds were similar between the core and periphery in hypoxic slices (Fig. 7A).

In addition to the $\mathrm{K}^{+}$wave, we also observed depth-dependent differences in propagation of the 
A)

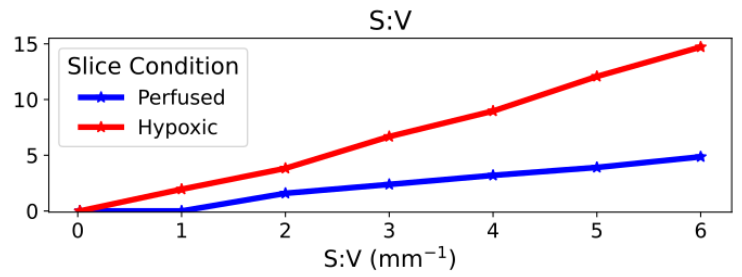

$$
\text { C) }
$$

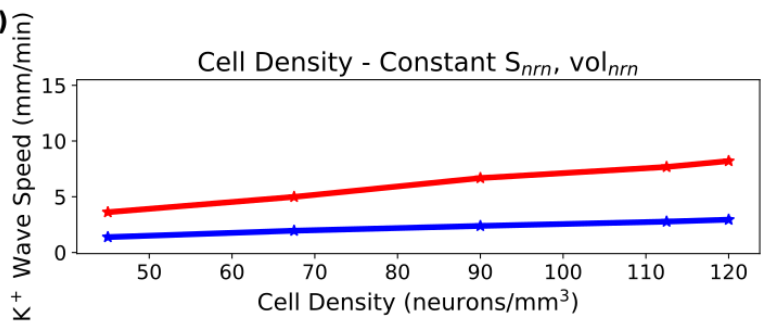

B)

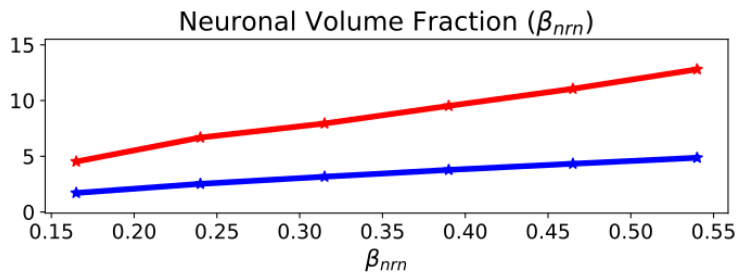

D)

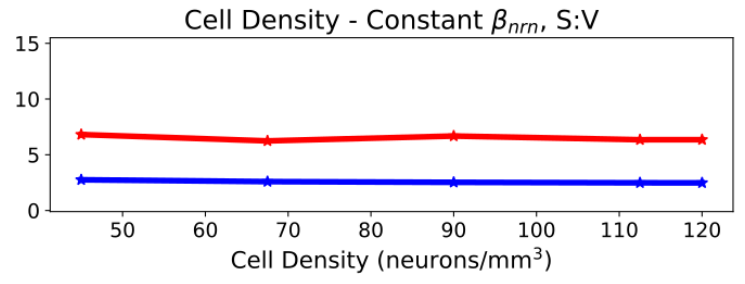

E)

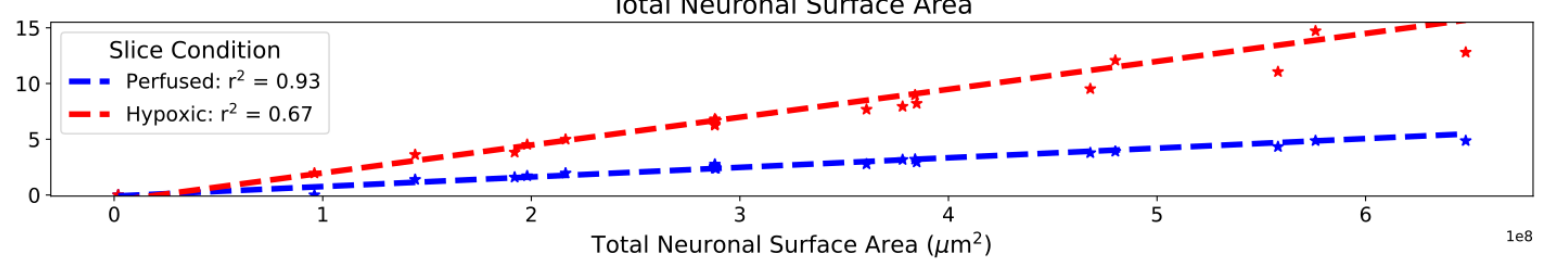

Figure 6: $\mathbf{K}^{+}$wave propagation speed was proportional to total neuronal surface area in the tissue. Effects of varying A S:V (0 speed - no wave); B. $\beta_{\mathrm{nrn}}$; C. density, constant S,V; D. density, constant $\beta_{\mathrm{nrn}}$. E. Pooled results: $\mathrm{K}^{+}$wave speed increased linearly with total neuronal surface area in both perfused and hypoxic slices.

depolarization wave (the SD itself) and neuronal spike rates in perfused slice (Fig. 8); spike rate represents a local tissue measure which could be more readily observed experimentally. While a $\mathrm{K}^{+}$wave propagated through the center of the slice (Fig. 8A), neurons in the periphery of the slice only underwent a modest depolarization and fired regularly at $10-70 \mathrm{~Hz}$, without the stereotyped bursting characteristic of SD (Fig. 8B). By contrast, SD at the periphery of the hypoxic slice kept closely behind SD in the core, with cells beyond $300 \mu \mathrm{m}$ from the center of the $\mathrm{K}^{+}$bolus firing almost simultaneously in core and periphery (Fig. 8C,D). 
A) Influence of Slice Thickness $\boldsymbol{\&}$ Depth

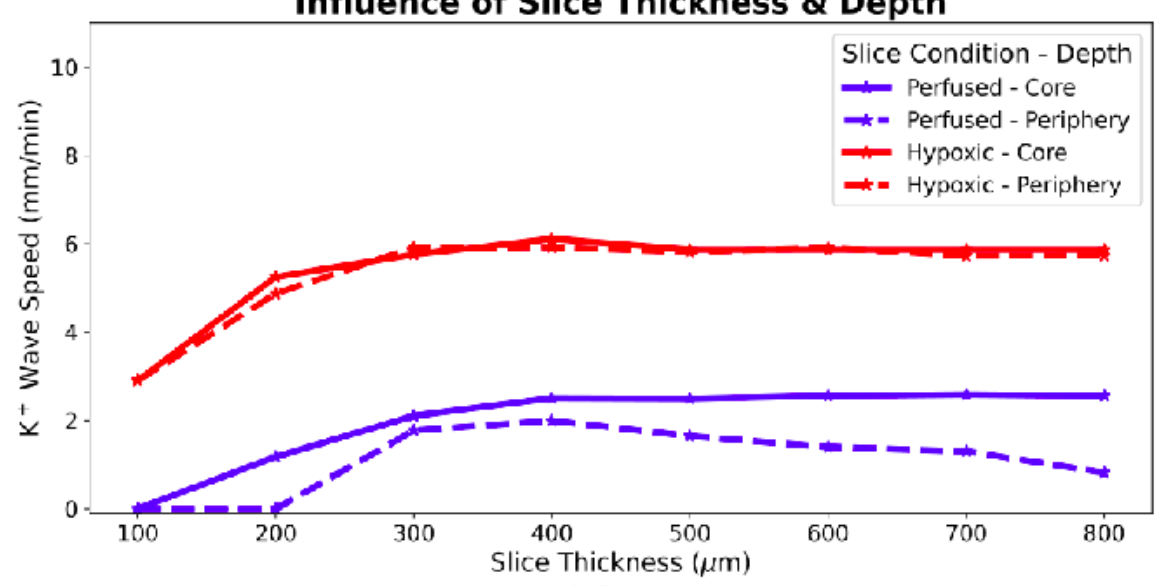

B)

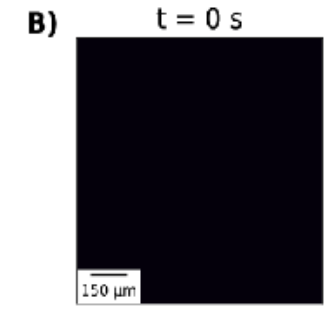

$\mathrm{t}=2.5 \mathrm{~s}$

Periphery
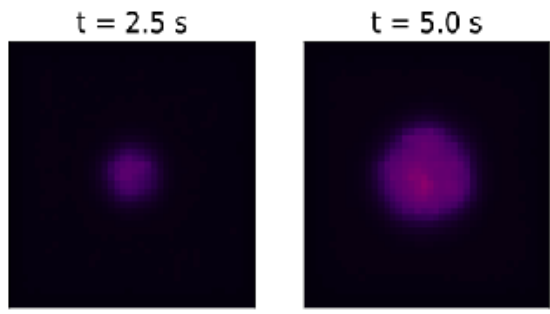

C)
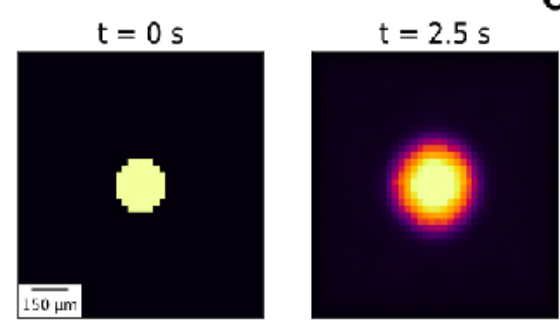

\section{Core}
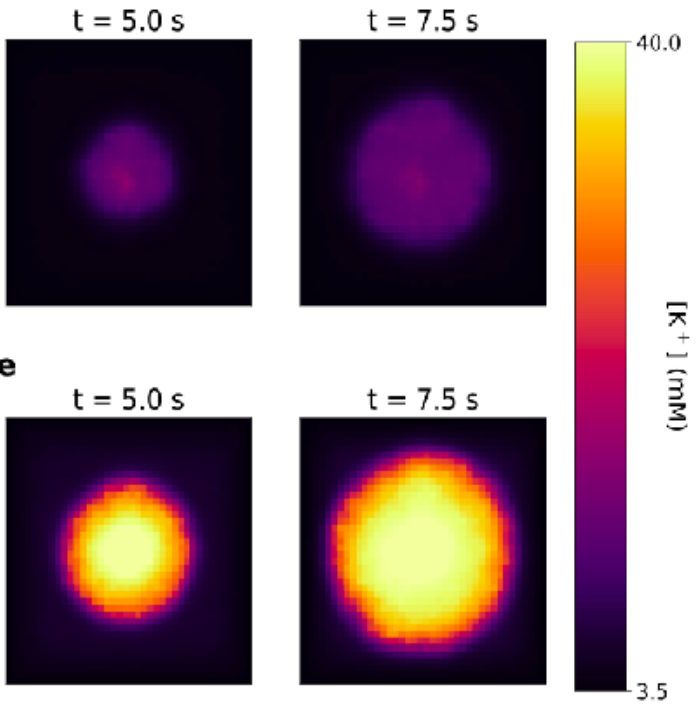

Figure 7: Slice thickness and within-slice position effects. A. $\mathrm{K}^{+}$wave speed in core $( \pm 50 \mu \mathrm{m}$ of center $)$ and periphery (within $50 \mu \mathrm{m}$ of bath) in perfused and hypoxic slices. B. Periphery: $\left[\mathrm{K}^{+}\right]_{\mathrm{ECS}}$ in perfused slice at 4 time points. C. Core: $\left[\mathrm{K}^{+}\right]_{\mathrm{ECS}}$ in same slice, same times. 


\section{Depth Dependent SD Propagation}

A)
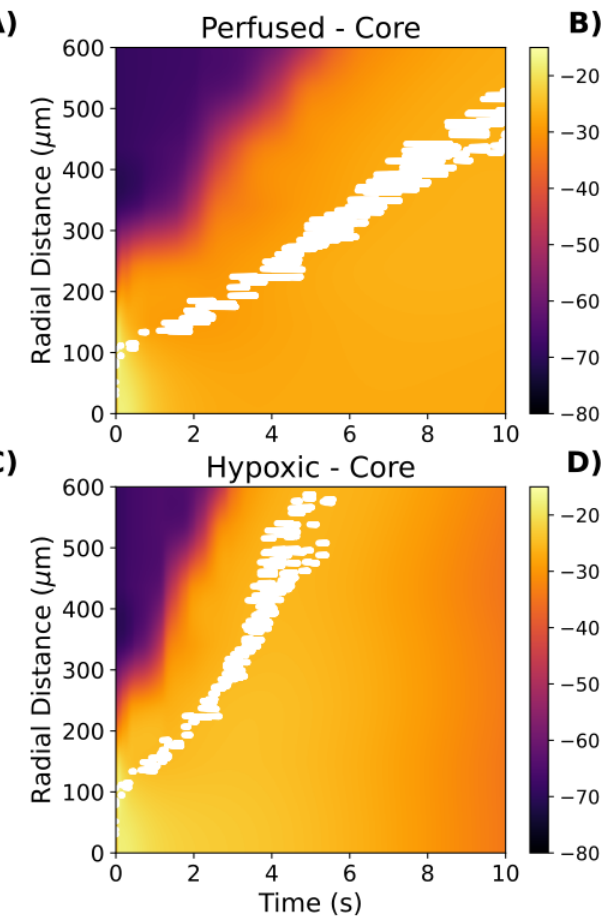

B)
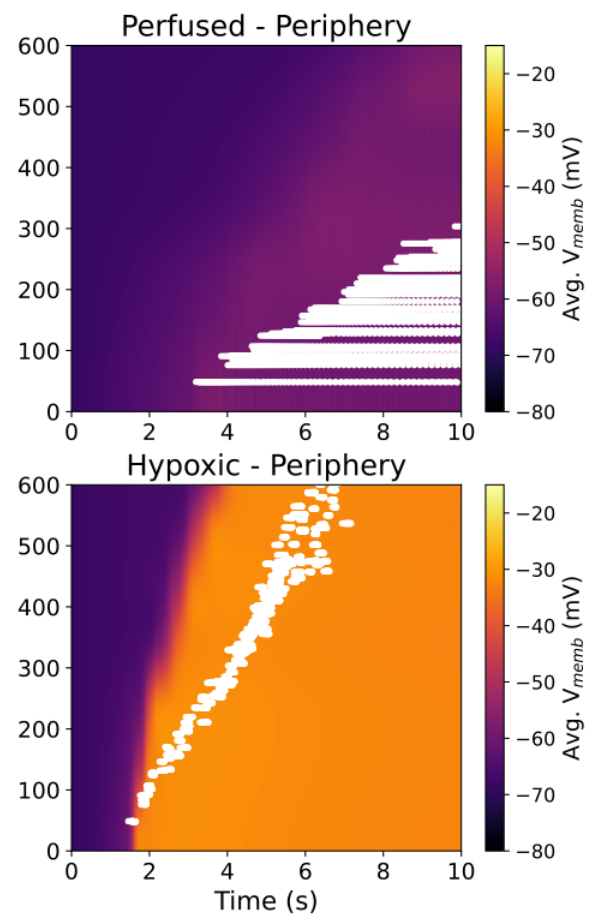

Figure 8: Pronounced depth-dependence of SD propagation in perfused slice Average $\mathrm{V}_{\text {memb }}$ (all cells) and spike rasters (white, $0.7 \%$ sampling) in $25 \mu \mathrm{m} \times 25 \mu \mathrm{m}$ voxels. A. perfused slice core, B. perfused slice periphery C. hypoxic slice core; D. hypoxic slice periphery. 


\section{Discussion}

Our model reproduced a number of the properties of SD observed in brain slices (Fig. 2,4). Slice models which most resembled cortical gray matter (high cell density, high neuronal S:V) showed SD speeds and neuronal firing patterns comparable to in vitro optical and electrophysiological measurements [Aitken et al., 1998, Hrabe and Hrabetova, 2019, Devin Brisson et al., 2013, Lemaire et al., 2021]. The all-or-none nature of SD initiation, as well as the observed bolus $\left[\mathrm{K}^{+}\right]$threshold of $\sim 20 \mathrm{mM}$, was also in agreement with experiments in brain slices [Andrew et al., 2017].

Our simulations suggest a pathological cycle whereby SD induces, and is also exacerbated by, hypoxia in slice. This mirrors findings in vivo where SD-associated metabolic demand for $\mathrm{O}_{2}$ can exceed supply, resulting in tissue hypoxia [Takano et al., 2007]. While $\mathrm{K}^{+}$was slowly spreading outward across the slice, $\mathrm{O}_{2}$ spread inward, following the gradient caused by $\mathrm{O}_{2}$ depletion from overworked pumps (compare rapid fall-off of $\mathrm{O}_{2}$ in Fig. 4E to much slower fall-off of $\left[\mathrm{K}^{+}\right]_{\mathrm{i}}$ in $4 \mathrm{~B}$ ). Depending on the distance to the bath and to the inciting bolus, intermediate locations in the slice will suffer various degrees of pump demand and partial pump failure. These spatiotemporal dynamics will be substantially altered by the effects of synaptic connectivity among cells, which remains to be explored.

By comparing the effects of changing $\mathrm{O}_{2}$ availability, total $\mathrm{Cl}^{-}$content, $\alpha_{E C S}$, and $\lambda_{E C S}$ on SD in isolation, we determined that $\alpha_{E C S}$ influenced SD most strongly (Fig. 5C), accounting for most of the speed-up observed in hypoxic and propionate-treated slices. Our results support the hypothesis that the main mechanism in propionate's priming for SD is through reducing $\alpha_{E C S}$ [Hrabe and Hrabetova, 2019], and suggest that the main mechanism for hypoxia speed-up is also reduced $\alpha_{E C S}$.

Our results support Grafstein's hypothesis that SD is primarily a reaction-diffusion process mediated by a regenerative $\mathrm{K}^{+}$wave [Grafstein, 1956]. Grafstein's hypothesis remains controversial [Strong, 2005, Herreras, 2005, Rogawski, 2008], but it is notable that even if synaptic or gap junction connectivity is necessary for $\mathrm{SD}$, the speed of $\mathrm{SD}$ is maintained as if it were governed principally by diffusion, and the regenerative $\mathrm{K}^{+}$source provided by the neurons in the path of the oncoming wave. 


\section{Model limitations}

A mild irony of our study is that we are computer modeling an in vitro model of an in vivo animal model of human pathophysiology (model of a model of a model). There are necessarily distortions at each step. At the computer modeling level, the major limitations of this study are the limitations that are inherent in all computer modeling - - we necessarily made choices as to what to include and what to leave out. In the current set of simulations, we left out: 1. all neural connectivity; 2. types of neurons, including distinction between inhibitory and excitatory neurons; 3. dendritic morphologies + additional membrane mechanisms; 4. glia, except as a generalized field; 5. volume occupying structures (instead using fractional volumes); 6. intracellular handling of ions and second messengers with effects on pumps and other mechanisms. These are largely correctable limitations that we will gradually begin to address in future versions of the model. Some, however, represent limitations in experimental knowledge which need to be addressed.

Additionally, we purposely designed the model to be generic rather than to reproduce the properties of any particular brain region and species. We feel this allows us to generalize more readily - e.g., comparing SD in brainstem vs cortex. Several interdependent tissue properties were treated independently with the benefit of allowing additional investigation by isolating parameters.

\section{Experimentally Testable Predictions}

Several of our predictions relate to the effects of manipulations on SD speed. These effects could be most easily assessed electrophysiologically by using a series of extracellular electrodes in slice to note the time of population burst passage and subsequent time of silence (the depression phase).

1. Slower SD in brainstem slice compared to cortical slice. Compared to cortex, brainstem has lower cell density, higher $\alpha_{E C S}$, and low expression of ECS matrix molecules/perineural nets, implying low $\lambda_{E C S}$ [Ogawa et al., 1985, Hobohm et al., 1998, Syková and Nicholson, 2008], All of these factors contribute to slower propagation speeds in our model (Fig. 5C, 6) Our analysis of principal cell morphologies from brainstem also suggested an $\mathrm{S}: \mathrm{V}$ lower than those of neocortical principal cells, another factor contributing to slowing. 


\section{Increased SD speed with cytotoxic edema in penumbra after stroke or traumatic brain injury} (TBI). Cytotoxic edema will increase $\beta_{n r n}$, producing speed-up, which will be enhanced in the hypoxic condition (Fig. 6B). We note that oxygen deprivation alone can be used to induce SD [Balestrino et al., 1988, Aitken et al., 1991, Müller and Somjen, 1998].

3. Hypoxia will increase SD speed under multiple conditions. We note that some of the fastest SD speeds ( $\sim 9 \mathrm{~mm} / \mathrm{min}$ ) have been observed in patients after stroke [Woitzik et al., 2013].

4. Increasing $\alpha_{E C S}$ will attenuate SD propagation. This could be assessed using hypertonic saline to increase $\alpha_{E C S}$ [Kume-Kick et al., 2002]. Hypertonic saline is sometimes used in reducing intracranial pressure after TBI [Oddo et al., 2009, Mangat et al., 2020, Shi et al., 2020, Kamel et al., 2011], and might therefore also reduce SD in these patients.

5. Antiepileptic agents will reduce SD speed. We show here that dynamic changes in $\alpha_{E C S}$ due to $\mathrm{SD}$ itself speeds up the SD wave. Similar changes in $\alpha_{\mathrm{ECS}}$ have been seen with ictal phenomena in slice [Colbourn et al., 2021], allowing us to hypothesize that this may be the linkage between SD and $\alpha_{\mathrm{ECS}}$, presumably mediated through excessive release of neurotransmitters whether classical, peptidergic, or NO.

6. SD velocity will correlate with neural density, dendritic complexity and total neuronal volume across regions Measurements of SD in various brain regions and across species can be assessed. Density is determined with counts in Nissl stain. Dendritic complexity increases S:V and can be assessed on traced, biocytin-filled cells with measures such as we performed here. Total neuronal volume can be assessed by measuring ascorbic acid in tissue [Rice and Russo-Menna, 1998]. These effects could also be evaluated in tissue culture or in organoids.

\section{Increasing the diameter or concentration of the $\mathrm{K}^{+}$bolus used to initiate SD beyond their} thresholds will not change SD speed (Fig. 3).

\section{Ease of SD initiation and SD propagation speed will increase with increasing slice thickness} due to relatively hypoxic core (Fig. 7). SD will be difficult or impossible to initiate in very thin slices; however, expect additional damage due to slicing (see next item). Thick slices (1 mm) have 
been used as in vivo models of ischemia [Newman et al., 1988].

\section{In thick slices $(\geq \mathbf{4 0 0} \mu \mathrm{m})$ SD speed will be greater near the slice center than near the surface.}

Extracellular measures looking for bursting and subsequent depression at different depths could be performed to confirm this prediction. However, one may want to avoid measurement directly at the slice surface where neurons will have suffered damage due to slicing and therefore may exhibit additional pathology that could alter SD propagation.

\section{Future directions}

Our model incorporated quantitative data and simpler models from numerous sources and at multiple spatial scales to constitute a unified framework for simulating SD in brain slices. We propose the use of this framework as community tool for researchers in the field to test hypotheses; guide the design of new experiments; and incorporate new physiological, transcriptomic, proteomic, or anatomical data into the framework. The open-source, branchable, versioned GitHub repository can provide a dynamical database for SD simulations or modeling brain slices in general.

\section{References}

[Aitken et al., 1991] Aitken, P. G., Jing, J., Young, J., and Somjen, G. G. (1991). Ion channel involvement in hypoxia-induced spreading depression in hippocampal slices. Brain Res., 541(1):7-11.

[Aitken et al., 1998] Aitken, P. G., Tombaugh, G. C., Turner, D. A., and Somjen, G. G. (1998). Similar propagation of SD and hypoxic SD-like depolarization in rat hippocampus recorded optically and electrically. J. Neurophysiol., 80(3):1514-1521.

[Andrew, 2016] Andrew, R. D. (2016). The persistent vegetative state: Evidence that the lower brain survives because its neurons intrinsically resist ischemia. In Monti, M. M. and Sannita, W. G., editors, Brain Function and Responsiveness in Disorders of Consciousness, pages 119-144. Springer International Publishing, Cham.

[Andrew et al., 2017] Andrew, R. D., Hsieh, Y.-T., and Brisson, C. D. (2017). Spreading depolarization triggered by elevated potassium is weak or absent in the rodent lower brain. J. Cereb. Blood Flow 
Metab., 37(5):1735-1747.

[Balestrino et al., 1988] Balestrino, M., Aitken, P. G., Jones, L. S., and Somjen, G. G. (1988). The role of spreading Depression-Like hypoxic depolarization in irreversible neuron damage, and its prevention. In Somjen, G., editor, Mechanisms of Cerebral Hypoxia and Stroke, pages 291-301. Springer US, Boston, MA.

[Boudewijns et al., 2013] Boudewijns, Z. S. R. M., Groen, M. R., Lodder, B., McMaster, M. T. B., Kalogreades, L., de Haan, R., Narayanan, R. T., Meredith, R. M., Mansvelder, H. D., and de Kock, C. P. J. (2013). Layer-specific high-frequency action potential spiking in the prefrontal cortex of awake rats. Front. Cell. Neurosci., 7:99.

[Colbourn et al., 2021] Colbourn, R., Hrabe, J., Nicholson, C., Perkins, M., Goodman, J. H., and Hrabetova, S. (2021). Rapid volume pulsation of the extracellular space coincides with epileptiform activity in mice and depends on the NBCe1 transporter. J. Physiol., 599(12):3195-3220.

[Cozzolino et al., 2018] Cozzolino, O., Marchese, M., Trovato, F., Pracucci, E., Ratto, G. M., Buzzi, M. G., Sicca, F., and Santorelli, F. M. (2018). Understanding spreading depression from headache to sudden unexpected death. Front. Neurol., 9:19.

[Cressman et al., 2009] Cressman, Jr, J. R., Ullah, G., Ziburkus, J., Schiff, S. J., and Barreto, E. (2009). The influence of sodium and potassium dynamics on excitability, seizures, and the stability of persistent states: I. single neuron dynamics. J. Comput. Neurosci., 26(2):159-170.

[Devin Brisson et al., 2013] Devin Brisson, C., Lukewich, M. K., and David Andrew, R. (2013). A distinct boundary between the higher brain's susceptibility to ischemia and the lower brain's resistance. PLoS One, 8(11):e79589.

[Dreier, 2011] Dreier, J. P. (2011). The role of spreading depression, spreading depolarization and spreading ischemia in neurological disease. Nat. Med., 17(4):439-447.

[Grafstein, 1956] Grafstein, B. (1956). Mechanism of spreading cortical depression. J. Neurophysiol., 19(2):154-171. 
[Haynes, 2014] Haynes, W. M. (2014). CRC Handbook of Chemistry and Physics. CRC Press.

[Herreras, 2005] Herreras, O. (2005). Electrical prodromals of spreading depression void grafstein's potassium hypothesis. J. Neurophysiol., 94(5):3656; author reply 3656-7.

[Hobohm et al., 1998] Hobohm, C., Härtig, W., Brauer, K., and Brückner, G. (1998). Low expression of extracellular matrix components in rat brain stem regions containing modulatory aminergic neurons. $J$. Chem. Neuroanat., 15(3):135-142.

[Hrabe and Hrabetova, 2019] Hrabe, J. and Hrabetova, S. (2019). Time-Resolved integrative optical imaging of diffusion during spreading depression. Biophys. J., 117(10):1783-1794.

[Joshi and Andrew, 2001] Joshi, I. and Andrew, R. D. (2001). Imaging anoxic depolarization during ischemia-like conditions in the mouse hemi-brain slice. J. Neurophysiol., 85(1):414-424.

[Kamel et al., 2011] Kamel, H., Navi, B. B., Nakagawa, K., Hemphill, Iii, J. C., and Ko, N. U. (2011). Hypertonic saline versus mannitol for the treatment of elevated intracranial pressure: A meta-analysis of randomized clinical trials*. Crit. Care Med., 39(3):554.

[Keller et al., 2018] Keller, D., Erö, C., and Markram, H. (2018). Cell densities in the mouse brain: A systematic review. Front. Neuroanat., 12:83.

[Kubota, 2014] Kubota, Y. (2014). Untangling GABAergic wiring in the cortical microcircuit. Curr. Opin. Neurobiol., 26:7-14.

[Kume-Kick et al., 2002] Kume-Kick, J., Mazel, T., Vorisek, I., Hrabĕtová, S., Tao, L., and Nicholson, C. (2002). Independence of extracellular tortuosity and volume fraction during osmotic challenge in rat neocortex. J. Physiol., 542(Pt 2):515-527.

[Larkum et al., 2004] Larkum, M. E., Senn, W., and Lüscher, H.-R. (2004). Top-down dendritic input increases the gain of layer 5 pyramidal neurons. Cereb. Cortex, 14(10):1059-1070.

[Lemaire et al., 2021] Lemaire, L., Desroches, M., Krupa, M., Pizzamiglio, L., Scalmani, P., and Mantegazza, M. (2021). Modeling NaV1.1/SCN1A sodium channel mutations in a microcircuit with 
realistic ion concentration dynamics suggests differential GABAergic mechanisms leading to hyperexcitability in epilepsy and hemiplegic migraine. PLoS Comput. Biol., 17(7):e1009239.

[Mangat et al., 2020] Mangat, H. S., Wu, X., Gerber, L. M., Schwarz, J. T., Fakhar, M., Murthy, S. B., Stieg, P. E., Ghajar, J., and Härtl, R. (2020). Hypertonic saline is superior to mannitol for the combined effect on intracranial pressure and cerebral perfusion pressure burdens in patients with severe traumatic brain injury. Neurosurgery, 86(2):221-230.

[Martins-Ferreira et al., 2000] Martins-Ferreira, H., Nedergaard, M., and Nicholson, C. (2000).

Perspectives on spreading depression. Brain Res. Brain Res. Rev., 32(1):215-234.

[Mazel et al., 2002] Mazel, T., Richter, F., Vargová, L., and Syková, E. (2002). Changes in extracellular space volume and geometry induced by cortical spreading depression in immature and adult rats. Physiol. Res., 51 Suppl 1:S85-93.

[McDougal et al., 2013] McDougal, R. A., Hines, M. L., and Lytton, W. W. (2013). Reaction-diffusion in the NEURON simulator. Front. Neuroinform., 7:28.

[Meyer et al., 2010] Meyer, H. S., Wimmer, V. C., Hemberger, M., Bruno, R. M., de Kock, C. P. J., Frick, A., Sakmann, B., and Helmstaedter, M. (2010). Cell type-specific thalamic innervation in a column of rat vibrissal cortex. Cereb. Cortex, 20(10):2287-2303.

[Müller and Somjen, 1998] Müller, M. and Somjen, G. G. (1998). Inhibition of major cationic inward currents prevents spreading depression-like hypoxic depolarization in rat hippocampal tissue slices. Brain Res., 812(1-2):1-13.

[Newman et al., 1988] Newman, G. C., Hospod, F. E., and Wu, P. (1988). Thick brain slices model the ischemic penumbra. J. Cereb. Blood Flow Metab., 8(4):586-597.

[Newton et al., 2018] Newton, A. J. H., McDougal, R. A., Hines, M. L., and Lytton, W. W. (2018). Using NEURON for Reaction-Diffusion modeling of extracellular dynamics. Front. Neuroinform., 12:41.

[Núñez-Abades et al., 1994] Núñez-Abades, P. A., He, F., Barrionuevo, G., and Cameron, W. E. (1994). Morphology of developing rat genioglossal motoneurons studied in vitro: changes in length, branching 
pattern, and spatial distribution of dendrites. J. Comp. Neurol., 339(3):401-420.

[Oddo et al., 2009] Oddo, M., Levine, J. M., Frangos, S., Carrera, E., Maloney-Wilensky, E., Pascual, J. L., Kofke, W. A., Mayer, S. A., and LeRoux, P. D. (2009). Effect of mannitol and hypertonic saline on cerebral oxygenation in patients with severe traumatic brain injury and refractory intracranial hypertension. J. Neurol. Neurosurg. Psychiatry, 80(8):916-920.

[Ogawa et al., 1985] Ogawa, Y., Eins, S., and Wolff, J. R. (1985). Oligodendrocytes in the pons and middle cerebellar peduncle of the cat. topographical relations to neurons and transverse axon bundles. Cell Tissue Res., 240(3):541-552.

[Øyehaug et al., 2012] Øyehaug, L., Østby, I., Lloyd, C. M., Omholt, S. W., and Einevoll, G. T. (2012). Dependence of spontaneous neuronal firing and depolarisation block on astroglial membrane transport mechanisms. J. Comput. Neurosci., 32(1):147-165.

[Payne et al., 2003] Payne, J. A., Rivera, C., Voipio, J., and Kaila, K. (2003). Cation-chloride co-transporters in neuronal communication, development and trauma. Trends Neurosci., 26(4):199-206.

[Pérez-Pinzón et al., 1995] Pérez-Pinzón, M. A., Tao, L., and Nicholson, C. (1995). Extracellular potassium, volume fraction, and tortuosity in rat hippocampal CA1, CA3, and cortical slices during ischemia. J. Neurophysiol., 74(2):565-573.

[Radman et al., 2009] Radman, T., Ramos, R. L., Brumberg, J. C., and Bikson, M. (2009). Role of cortical cell type and morphology in subthreshold and suprathreshold uniform electric field stimulation in vitro. Brain Stimul., 2(4):215-28, 228.e1-3.

[Raslan et al., 2014] Raslan, A., Ernst, P., Werle, M., Thieme, H., Szameit, K., Finkensieper, M., Guntinas-Lichius, O., and Irintchev, A. (2014). Reduced cholinergic and glutamatergic synaptic input to regenerated motoneurons after facial nerve repair in rats: potential implications for recovery of motor function. Brain Struct. Funct., 219(3):891-909.

[Rice and Russo-Menna, 1998] Rice, M. E. and Russo-Menna, I. (1998). Differential compartmentalization of brain ascorbate and glutathione between neurons and glia. Neuroscience, 82(4):1213-1223. 
[Rogawski, 2008] Rogawski, M. A. (2008). Common pathophysiologic mechanisms in migraine and epilepsy. Arch. Neurol., 65(6):709-714.

[Ros et al., 2010] Ros, H., Magill, P. J., Moss, J., Bolam, J. P., and Mena-Segovia, J. (2010). Distinct types of non-cholinergic pedunculopontine neurons are differentially modulated during global brain states. Neuroscience, 170(1):78-91.

[Samson et al., 2003] Samson, E., Marchand, J., and Snyder, K. A. (2003). Calculation of ionic diffusion coefficients on the basis of migration test results. Mater. Struct., 36(3):156-165.

[Shi et al., 2020] Shi, J., Tan, L., Ye, J., and Hu, L. (2020). Hypertonic saline and mannitol in patients with traumatic brain injury: A systematic and meta-analysis. Medicine, 99(35):e21655.

[Sivagnanam et al., 2013] Sivagnanam, S., Majumdar, A., Yoshimoto, K., Astakhov, V., Bandrowski, A., Martone, M., and Carnevale, N. (2013). Introducing the neuroscience gateway. IWSG.

[Strong, 2005] Strong, A. J. (2005). Dr. bernice grafstein's paper on the mechanism of spreading depression. J. Neurophysiol., 94(1):5-7.

[Syková and Nicholson, 2008] Syková, E. and Nicholson, C. (2008). Diffusion in brain extracellular space. Physiol. Rev., 88(4):1277-1340.

[Takano et al., 2007] Takano, T., Tian, G.-F., Peng, W., Lou, N., Lovatt, D., Hansen, A. J., Kasischke, K. A., and Nedergaard, M. (2007). Cortical spreading depression causes and coincides with tissue hypoxia. Nat. Neurosci., 10(6):754-762.

[Tao et al., 2002] Tao, L., Masri, D., Hrabetová, S., and Nicholson, C. (2002). Light scattering in rat neocortical slices differs during spreading depression and ischemia. Brain Res., 952(2):290-300.

[Vetter et al., 2001] Vetter, P., Roth, A., and Häusser, M. (2001). Propagation of action potentials in dendrites depends on dendritic morphology. J. Neurophysiol., 85(2):926-937.

[Wei et al., 2014] Wei, Y., Ullah, G., and Schiff, S. J. (2014). Unification of neuronal spikes, seizures, and spreading depression. J. Neurosci., 34(35):11733-11743. 
[Williams et al., 2019] Williams, P. A., Dalton, C., and Wilson, C. G. (2019). Modeling hypoglossal motoneurons in the developing rat. Respir. Physiol. Neurobiol., 265:40-48.

[Woitzik et al., 2013] Woitzik, J., Hecht, N., Pinczolits, A., Sandow, N., Major, S., Winkler, M. K. L., Weber-Carstens, S., Dohmen, C., Graf, R., Strong, A. J., Dreier, J. P., Vajkoczy, P., and COSBID study group (2013). Propagation of cortical spreading depolarization in the human cortex after malignant stroke. Neurology, 80(12):1095-1102.

[Zandt et al., 2015] Zandt, B.-J., ten Haken, B., van Putten, M. J. A. M., and Dahlem, M. A. (2015). How does spreading depression spread? physiology and modeling. Rev. Neurosci., 26(2):183-198.

[Zoremba et al., 2008] Zoremba, N., Homola, A., Šlais, K., Voříšek, I., Rossaint, R., Lehmenkühler, A., and Syková, E. (2008). Extracellular diffusion parameters in the rat somatosensory cortex during recovery from transient global ischemia/hypoxia. Journal of Cerebral Blood Flow \& Metabolism, 28(10):1665-1673. 